\title{
ENGENHARIA DE EMPREENDIMENTOS SUSTENTÁVEIS: CLASSES DE USO E NÍVEIS DE CERTIFICAÇÃO DOS EMPREENDIMENTOS CERTIFICADOS NO ESTADO DE SÃO PAULO
}

\section{Engineering of sustainable developments: Use classes and levels of certification of certified developments in the State of São Paulo}

\author{
Marco Antonio Campos ${ }^{1}$, André Munhoz de Argollo Ferrão ${ }^{2}$
}

Recebido em 03 de janeiro de 2017; aceito em 06 de setembro de 2017; disponível on-line em 07 de novembro de 2017.

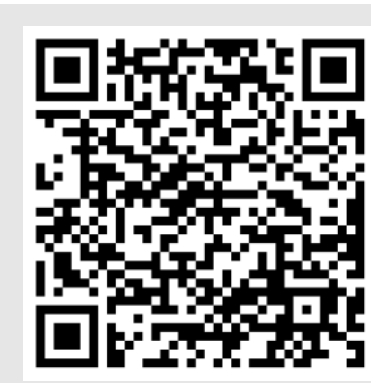

PALAVRAS CHAVE:

Sustentabilidade; Engenharia de empreendimentos; Selo verde; Construção civil; Empreendimentos sustentáveis.

\section{KEYWORDS:}

Sustainability;

Projects engineering;

Green label;

Civil construction;

Sustainable projects.

\footnotetext{
* Contato com os autores:
}

${ }^{1}$ e-mail: engenheiromarcoantonio@hotmail.com (M. A. Campos)

Engenheiro Civil, Doutor em Engenharia Civil, Pesquisador Colaborador do Labore - Laboratório de Empreendimentos da Faculdade de Engenharia Civil, Arquitetura e Urbanismo - FEC, da Universidade Estadual de Campinas - UNICAMP.

2e-mail: argollo@fec.unicamp.br ( A. M. de Argollo Ferrão )

Engenheiro Civil, Doutor em Arquitetura e Urbanismo, Coordenador do Labore - Laboratório de Empreendimentos, Professor Livre Docente da Faculdade de Engenharia Civil, Arquitetura e Urbanismo - FEC, da Universidade Estadual de Campinas - UNICAMP.

\begin{abstract}
Environmental sustainability actions are directly linked to real estate developments. In Brazil there has been increasing interest in these certifications in recent years. At present, there are seven certifying agencies operating in Brazil, four of which are international organizations that have been adapted to the domestic market and three of which are home-grown organizations. Each of them has its own methodology and certification analysis parameters. São Paulo is the Brazilian state which concentrates the greatest number of developments. Therefore, this article presents each certification body's characteristics and the certification classes and levels of the certified developments in the state of São Paulo, by means of analysis of the data provided by these organizers on their websites. Contributing to future studies in other states, in addition to classification with data from the national construction market, creating a database in relation to this certification market that has been growing in recent years and which will be a future trend for differentiation of real estate launches.
\end{abstract}

RESUMO: Ações de sustentabilidade ambiental estão ligadas diretamente aos empreendimentos imobiliários. No Brasil a busca por estas certificações vem atuantes no país, sendo quatro organismos internacionais adaptados ao mercado empreendimentos. Portanto, este artigo apresenta as características de cada certificados no estado de São Paulo, através da análise dos dados disponibilizados por estes organizadores em seus sites. Contribuindo para estudos futuros em outros criando uma base de dados deste mercado de certificações que vem crescendo nos últimos anos e será tendência futura para diferenciação dos lançamentos imobiliários. 


\section{INTRODUÇÃO}

Por ser o setor que mais consome recursos naturais, utiliza energia de forma intensiva e responsável por mais de $50 \%$ dos resíduos sólidos gerados, a construção civil vem buscando nos últimos anos ações de sustentabilidade para seus empreendimentos.

Ações estas que se resumem na redução e otimização do consumo de materiais e energia, na redução dos resíduos gerados, na preservação do ambiente natural e na melhoria da qualidade do ambiente construído. Quando bem planejadas e executadas estas ações o empreendimento pode receber, através de um organismo certificador externo, mediante contratação, a certificação de sustentabilidade do empreendimento. (CAIXA, 2010; MMA, s.d.)

Com esta prática recente e crescente atualmente há sete organismos certificadores atuando no Brasil, sendo três deles fruto de ações governamentais como do Ministério de Minas e Energia, com a criação do Selo Procel Edificações exclusivo ao consumo de energia, Caixa Econômica Federal com o Selo Casa Azul Caixa - enfatiza a redução de impactos ambientais aplicados à construção, utilização, ocupação e manutenção das edificações, e a iniciativa da Prefeitura Municipal do Rio de Janeiro com a certificação Qualiverde, com critérios de sustentabilidade para as obras das Olimpíadas de 2016.

Os demais certificadores são selos internacionais que foram adaptados as normas nacionais. Dois certificadores atuam há vários anos no Brasil como o selo AQUA-HQE, França, e o LEED, Estados Unidos. Já os selos BREEAM, Grã-Bretanha, e DNGB, Alemanha, estão em fase de implantação no mercado.

\subsection{OBJETIVOS}

Com a análise do mercado nacional, e em especial aos dados do estado de São Paulo o objeto deste trabalho foi inicialmente caracterizar os organismos certificadores de construção sustentável atuantes no Brasil, destacando suas particularidades e diferenciais. Seguida da análise das classes e níveis de classificação dos empreendimentos certificados, destacando os dados no estado de São Paulo, que é o estado que concentra a maior quantidade de certificações no Brasil, contribuindo para a formação de uma base de dados que poderá ser expandida para os demais estados.

\section{METODOLOGIA}

Os organismos certificadores de construção sustentável atuantes no Brasil disponibilizam em seus sites informações referentes a sua metodologia de certificação, empreendimentos certificados e localização. Portanto, este trabalho analisou os dados de todos estes organismos elaborando tabelas com critérios de desempenho analisados para a certificação, seguido da análise da localização de cada empreendimento certificado no estado de São Paulo, acompanhado da classe de uso da edificação certificada.

\section{OS ORGANISMOS CERTIFICADORES NO BRASIL}

No Brasil são sete os organismos certificadores de empreendimentos sustentáveis da construção civil, sendo três exclusivamente nacionais, Procel Edificações (PROCEL, 2016), Selo Casa Azul Caixa (CAIXA, 2016), Qualiverde (PMRJ, 2016), e quatro internacionais: AQUA-HQE (AQUA, 2016), BREEAM (BREEAM, 2016), DNGB (DGNB, 2016) e LEED (LEED, 2016). Na Tabela 1 são apresentados os certificadores nacionais, e na Tabela 2 tem-se os critérios de desempenho e os diferenciais de cada um desses organismos brasileiros. 
TABELA 1: Apresentação Geral dos certificadores nacionais.

\begin{tabular}{|c|c|c|c|}
\hline Informações & Procel Edifica & Qualiverde & Selo Casa Azul Caixa \\
\hline Organismo mantenedor & ELETROBRAS/PROCEL & $\begin{array}{c}\text { Prefeitura Municipal do } \\
\text { Rio de Janeiro }\end{array}$ & Ministério das Cidades \\
\hline Organismo certificador & $\begin{array}{c}\text { Programa Nacional de Eficiência } \\
\text { Energética em Edificações }\end{array}$ & $\begin{array}{c}\text { Secretaria de Urbanismo - } \\
\text { PMRJ }\end{array}$ & $\begin{array}{c}\text { Caixa Econômica } \\
\text { Federal }\end{array}$ \\
\hline Ano de lançamento & 2.003 & 2.011 & 2.010 \\
\hline $\begin{array}{l}\text { Empreendimentos } \\
\text { certificados ou em fase } \\
\text { de certificação }\end{array}$ & $\begin{array}{l}\text { Mais de } 3.100 \text { certificações, } \\
\text { incluindo unidades autônomas }\end{array}$ & Sem dados & $\begin{array}{l}19 \text { empreendimentos } \\
\text { certificados }\end{array}$ \\
\hline Objetivos & $\begin{array}{l}\text { O PROCEL visa promover o uso } \\
\text { racional da energia elétrica em } \\
\text { edificações desde sua fundação, } \\
\text { sendo que, com a criação do Procel } \\
\text { Edifica, as ações foram ampliadas e } \\
\text { organizadas com o objetivo de } \\
\text { incentivar a conservação e o uso } \\
\text { eficiente dos recursos naturais (água, } \\
\text { luz, ventilação) nas edificações, } \\
\text { reduzindo os desperdícios e os } \\
\text { impactos sobre o meio ambiente. }\end{array}$ & $\begin{array}{l}\text { Elaborar critérios de } \\
\text { sustentabilidade para as } \\
\text { obras das Olimpíadas de } \\
2016\end{array}$ & $\begin{array}{l}\text { Reconhecer e incentivar } \\
\text { projetos que } \\
\text { demonstrem suas } \\
\text { contribuições à redução } \\
\text { de impactos ambientais, } \\
\text { adotando soluções mais } \\
\text { eficientes aplicadas à } \\
\text { construção, utilização, } \\
\text { ocupação e } \\
\text { manutenção das } \\
\text { edificações, } \\
\text { promovendo o uso } \\
\text { racional de recursos } \\
\text { naturais e a melhoria da } \\
\text { qualidade da habitação } \\
\text { e de seu entorno. }\end{array}$ \\
\hline
\end{tabular}

TABELA 2: Critérios de desempenho e diferenciais dos certificadores nacionais.

\begin{tabular}{ll} 
Certificação & Avaliação dos critérios \\
\hline & \\
& 4 critérios referente a: - \\
& Envoltória \\
PROCEL Edificações & - Iluminação \\
& - Condicionamento de ar \\
& - Aquecimento de água
\end{tabular}

\section{Qualiverde}

Avaliação em 4 tópicos de ações referente a: Gestão da água, Eficiência energética e desempenho térmico, Projeto e Bonificações
Avaliação de desempenho

Classificação do nível de eficiência energética pode variar de $A$ (mais eficiente) a

$\mathrm{E}$ (menos eficiente). Classificação relacionada à pontuação total alcançada pelo edifício, após avaliação de cada sistema individual associado a um peso.

$70 \%$ dos pontos nas ações de sustentabilidade propostas no Decreto Qualiverde.

$O$ decreto envolve diversas ações relativas a Gestão da Água, Eficiência Energética, Desempenho Térmico e Projeto.

\section{Diferenciais}

Selo Procel amplamente utilizado e familiar aos consumidores. Requisitos desenvolvidos pela Secretaria Técnica de Edificações, coordenada pelo Procel e pelo LabEEE da UFSC, e participação de diversas universidades brasileiras. Concessão de benefícios às construções "verdes", em duas esferas: DECRETO QUALIVERDE: qualifica os projetos que adotarem ações de sustentabilidade; LEIS DE BENEFÍCIOS: concede benefícios edilícios e fiscais aos projetos qualificados. 
TABELA 2: Critérios de desempenho e diferenciais dos certificadores nacionais. (CONTINUAÇÃO).

\begin{tabular}{|c|c|c|c|}
\hline Certificação & Avaliação dos critérios & Avaliação de desempenho & Diferenciais \\
\hline Selo Casa Azul Caixa & $\begin{array}{l}\text { Avaliação de critérios } \\
\text { divididos em } 6 \text { categorias: } \\
\text { - Qualidade urbana: } 5 \\
\text { - Projeto e conforto: } 11 ; \\
\text { - Eficiência energética: } 8 ; \\
\text { - Conservação de recursos e } \\
\text { materiais: } 10 \text { critérios; } \\
\text { - Gestão da água: } 8 ; \\
\text { - Práticas sociais: } 11 .\end{array}$ & $\begin{array}{l}\text { Categoria Bronze: se aplica } \\
\text { somente a habitações de } \\
\text { interesse social, devem ser } \\
\text { atendidos no mínimo } 19 \\
\text { critérios obrigatórios. } \\
\text { Categoria Prata: atendidos os } \\
19 \text { critérios obrigatórios e } 6 \\
\text { critérios de livre escolha. } \\
\text { Categoria Ouro: } 19 \text { critérios } \\
\text { obrigatórios e } 12 \text { critérios de } \\
\text { livre escolha }\end{array}$ & $\begin{array}{l}\text { - Adaptado à realidade } \\
\text { brasileira e seus diversos } \\
\text { aspectos regionais; } \\
\text { - Proporciona autonomia e } \\
\text { estimula as responsabilidades } \\
\text { do empreendedor; } \\
\text { - Valoriza as soluções para } \\
\text { resultados efetivos, } \\
\text { respeitando as } \\
\text { especificidades de cada } \\
\text { projeto; } \\
\text { - Possui auditorias } \\
\text { presenciais, reforçando a } \\
\text { rigorosidade e a credibilidade } \\
\text { da certificacão. }\end{array}$ \\
\hline
\end{tabular}

FONTE: CAMPOS, ARGOLLO FERRÃO, 2015.

A Tabela 3 apresenta as informações gerais dos certificadores internacionais atuantes no Brasil, seguido dos critérios de avaliação desempenho avaliados e diferenciais de cada um deles, AQUA-HQE - Tabela 4, BREEAM - Tabela 5, DNGB - Tabela 6, LEDD - Tabela 7.

\section{TABELA 3: Apresentação geral dos certificadores internacionais.}

\begin{tabular}{|c|c|c|c|c|}
\hline Informações & AQUA-HQE & BREEAM & DNGB & LEED \\
\hline País de origem & França & Inglaterra & Alemanha & $\begin{array}{c}\text { Estados Unidos da } \\
\text { América }\end{array}$ \\
\hline $\begin{array}{l}\text { Organismo } \\
\text { internacional }\end{array}$ & $\begin{array}{l}\text { HQE - Haute Qualité } \\
\text { Environnementale }\end{array}$ & $\begin{array}{l}\text { BRE - Building Reserch } \\
\text { Establishment }\end{array}$ & $\begin{array}{c}\text { German } \\
\text { Sustainable } \\
\text { Building Council } \\
\end{array}$ & $\begin{array}{l}\text { USGBC - United } \\
\text { States Green } \\
\text { Building Council } \\
\end{array}$ \\
\hline Ano de lançamento & 1.974 & 1.992 & 2.009 & 2.000 \\
\hline $\begin{array}{l}\text { Empreendimentos } \\
\text { certificados ou em fase } \\
\text { de certificação no } \\
\text { mundo }\end{array}$ & 2.800 .000 & 1.200 .000 & 450 & 150.000 \\
\hline Representante no Brasil & Fundação Vanzolini & Consultores Independentes & $\begin{array}{l}5 \text { Consultores } \\
\text { Independentes }\end{array}$ & $\begin{array}{c}\text { GBCB Green } \\
\text { Building Council } \\
\text { Brasil } \\
\end{array}$ \\
\hline Início atividades & 2.008 & 2.011 & & 2.007 \\
\hline $\begin{array}{l}\text { Empreendimentos } \\
\text { certificados ou em fase } \\
\text { de certificação no Brasil }\end{array}$ & $\begin{array}{l}493 \text { edificações e mais de } \\
10.000 \text { unidades } \\
\text { habitacionais certificadas }\end{array}$ & $\begin{array}{l}2 \text { empreendimentos em } \\
\text { fase de certificação }\end{array}$ & mercado brasileiro & 1.000 \\
\hline
\end{tabular}




\section{TABELA 4: Características certificação AQUA-HQE.}

\section{Avaliação dos critérios}

Avaliação de 14 critérios de sustentabilidade:

1. Relação do edifício com o seu entorno;

2. Escolha integrada de produtos, sistemas e processos construtivos; 3. Canteiro de obras de baixo impacto ambiental;

4. Gestão da energia;

5. Gestão da água;

6. Gestão de resíduos de uso e operação do edifício;

7. Manutenção e permanência do desempenho ambiental;

8. Conforto higrotérmico;

9. Conforto acústico;

10. Conforto visual;

11. Conforto olfativo;

12. Qualidade sanitária dos ambientes;

13. Qualidade sanitária do ar, e;

14. Qualidade sanitária da água.
Avaliação de desempenho

Três níveis de avaliação de desempenho:

- Bom: corresponde ao desempenho mínimo aceitável para um empreendimento de Alta Qualidade Ambiental. Pode corresponder à regulamentação, se esta for suficientemente exigente quanto aos desempenhos de um empreendimento ou, na ausência desta, à prática corrente;

- Superior: corresponde ao nível das boas práticas, e;

- Excelente: nível calibrado em função dos desempenhos máximos constatados em empreendimentos de Alta Qualidade Ambiental, desde que sejam atingíveis.

\section{Diferenciais}

- Adaptado à realidade brasileira e suas

heterogeneidades regionais;

- Possui alto grau de exigência;

- Possibilita flexibilidade de projeto e adoção de soluções compatíveis com o empreendimento;

- Estimula o empreendedor a participar diretamente do processo de certificação;

- Valoriza as soluções para resultados efetivos, respeitando as especificidades de cada projeto;

- Possui auditorias presenciais, reforçando a rigorosidade e credibilidade da certificação; - A Fundação Vanzolini, responsável pelo AQUA, tem reconhecimento nacional e internacional e está sediada no Brasil (São Paulo), o que facilita e agiliza o processo de certificação e desenvolvimento de novos sistemas; - Os referenciais de certificação estão em constante processo de aprimoramento, com a participação dos melhores profissionais que atuam ativamente na área de sustentabilidade no Brasil.

FONTE: Adaptado AQUA, 2016.

TABELA 5: Características certificação BREEAM.

\begin{tabular}{l} 
Avaliação dos critérios \\
\hline Nove critérios de avaliação: \\
- Energia - eficiência energética \\
e dióxido de carbono; \\
- Gerenciamento - política de \\
gerenciamento da obra; \\
- Saúde e Bem-estar - como som, \\
luz e qualidade do ar; \\
- Transporte - $\mathrm{CO}_{2}$ e localização \\
relacionados a transporte; \\
- Água - consumo e eficiência \\
das edificações; \\
- Materiais - impactos \\
incorporados nos materiais, \\
incluindo ciclo de vida e $\mathrm{CO}_{2} ;$ \\
- Resíduos - eficiência dos \\
recursos usados para construção \\
e gerenciamento dos seus \\
descartes; \\
- Uso da terra - pegada ecológica \\
dos edifícios e terrenos;
\end{tabular}

Avaliação de desempenho

Diferenciais

Avaliação baseada em pontuação e não exige o cumprimento de pré-requisitos.

São 100 pontos, distribuídos em nove categorias, com créditos que variam de peso:

$$
\begin{gathered}
\text { Pass - 30\%; } \\
\text { Good - 45\%; } \\
\text { Very Good - 55\%; } \\
\text { Excellent - 70\%; } \\
\text { Outstanding - 85\%. }
\end{gathered}
$$

- Rigor e profundidade de seus critérios, constantemente atualizados através da sua estreita relação com pesquisas acadêmicas e análise laboratorial do ciclo de vida de materiais; - Reconhecimento internacional, atuação em diversos países;

- Adaptabilidade, para ser aplicada em diferentes culturas, devido ao seu sistema que considera as diferenças regionais;

- Dá preferência à legislação local;

- Caráter prescritivo, estruturado a partir da prevenção de riscos e da preservação dos recursos naturais;

- Utiliza um sistema direto de pontuação que é transparente, flexível, fácil de entender, com base em comprovação científica e pesquisas; 
TABELA 5: Características certificação BREEAM. (CONTINUAÇÃO).

Avaliação dos critérios

- Poluição - controle de poluição do ar exterior e águas;

- Ecologia - valor ecológico e preservação do terreno.

\section{Avaliação de desempenho}

Avaliação baseada em pontuação e não exige o cumprimento de pré-requisitos.

São 100 pontos, distribuídos em nove categorias, com créditos que variam de peso:

Pass - 30\%;

Good - 45\%;

Very Good - 55\%;

Excellent - 70\%;

Outstanding - $85 \%$.
Diferenciais

- Gera e desenvolve diversos padrões técnicos com rigorosa qualidade, suportados por pesquisas de evidências, que garantem a redução de impactos ambientais, perdas, otimização de processos e custos operacionais do empreendimento;

- Usa sistema de pontuação claro, transparente e fácil de entender;

- Provê ferramentas para ajudar a medir, aprimorar a qualidade dos ambientes de trabalho e moradia, e reduzir custos;

- Capacita equipes de projetos envolvidas no processo de certificação a aprimorar sua experiência e conhecimentos de aspectos ambientais da sustentabilidade;

- Valoriza o empreendimento pelo crescente reconhecimento da respeitabilidade desta metodologia para edifícios de baixo impacto ambiental, e seu diferencial em relação aos demais sistemas de certificação.

FONTE: Adaptado BREEAM, 2016.

\section{TABELA 6: Características certificação DNGB}

\section{Avaliação dos critérios}

Seis grupos matrizes:

1. Qualidade Ambiental;

2. Qualidade Econômica;

3. Qualidade Socio-cultural e funcionalidade;

4. Qualidade Técnica;

5. Qualidade do Processo, e;

6. Qualidade do terreno (medida a parte).

\section{Avaliação de desempenho}

As categorias e seus respectivos critérios são analisados através de uma perspectiva abrangente, que vai do macro ao micro: o planeta, a cidade, a vizinhança, o edifício e os componentes da edificação.

Ao contrário dos outros sistemas, para a certificação DGNB a viabilidade econômica tem o mesmo peso das categorias ambientais, sociais e técnicas.

\section{Diferenciais}

- Sistema de alta qualidade que analisa o edifício como um todo e não incentiva a adoção de soluções pontuais e específicas;

- Sua abordagem é completa e analisa os impactos das soluções adotadas, desde o macro (global) até o micro (local);

- Flexível, para ser aplicado a diferentes culturas; - Garante um planejamento seguro através da clara definição de seus objetivos desde o início, diminuindo os riscos de investimento para os empreendedores;

- Garante menor taxa de desocupação dos imóveis e maior facilidade para locação, com valores de aluguel até $4 \%$ mais altos; - Garante menores custos operacionais e maior satisfação e produtividade dos ocupantes; - Flexibilidade para ser adaptado a futuros desenvolvimentos tecnológicos e sociais. 


\section{TABELA 7: Características certificação LEED.}

\section{Avaliação dos critérios}

Sete dimensões a serem avaliadas:

1. Sustainable sites (Espaço

Sustentável);

2. Water efficiency (Eficiência do uso da água);

3. Energy \& Atmosphere (Energia

e Atmosfera);

4. Materials \& Resources

(Materiais e Recursos);

5. Indoor environmental quality

(Qualidade ambiental interna);

6. Innovation in design or innovation in operations (Inovação e Processos); 7. Regional priority credits (Créditos de Prioridade Regional).
Avaliação de desempenho

Conta com itens pré-estabelecidos que devem ser alcançados para assegurar a viabilidade da certificação - mas não valem pontos. Os créditos são opcionais e podem ser escolhidos de acordo com a facilidade de sua aplicação, que varia de acordo com as especificidades de cada projeto. Critérios - Pontuação

1 - Espaço sustentável - 26

2 - Eficiência do uso da água - 10

3 - Energia e atmosfera - 35

4-Materiais e recursos - 14

5 - Qualidade ambiental interna - 15

6 - Inovação e processos - 6

7 - Créditos regionais - 4

Total - 110 pontos

Nível de Certificação - Pontuação

Platinum - 80 a 110 pontos

Ouro - 60 a 79 pontos

Prata - 50 a 59 pontos

Certificado - 40 a 49 pontos
Diferenciais

Facilidade de aplicação / organização de documentação devido à boa estruturação de seu sistema (fornecimento de modelos, check lists etc.); - Disseminação / divulgação eficiente;

- Reconhecimento internacional; - Critérios prescritivos e soluções pré-estabelecidas, e;

- Popularização das práticas sustentáveis através da elevação do valor comercial dos empreendimentos.

\section{NÍVEL DE CLASSIFICAÇÃO DOS EMPREENDIMENTOS CERTIFICADOS}

Além da diferença entre os organismos certificadores os próprios programas de certificação possuem pontuação e metas que devem ser atingidos por cada empreendimento e sua destinação de uso, como uma edificação destinada a educação, multifamiliar, serviços entre outros. Portanto, a Tabela 8 apresenta a quantidade de certificação de cada classe. Na Tabela 9, constam as quantidades de empreendimentos certificados e a porcentagem de cada classe no total de certificação.

TABELA 8: Quantidade de empreendimentos certificados no Estado de São Paulo e suas classes de uso.

\begin{tabular}{|c|c|c|c|c|c|c|c|}
\hline \multirow{2}{*}{$\begin{array}{c}\text { Tipo de } \\
\text { empreendimento }\end{array}$} & \multicolumn{7}{|c|}{ Organismos Certificadores } \\
\hline & LEED & $\begin{array}{c}\text { AQUA- } \\
\text { HQE }\end{array}$ & $\begin{array}{c}\text { SELO CASA } \\
\text { AZUL }\end{array}$ & $\begin{array}{c}\text { Procel } \\
\text { Edificações }\end{array}$ & BREEAM & $\begin{array}{l}\text { QUALIVERDE - } \\
\text { PMRJ }\end{array}$ & DGNB \\
\hline Arena Esportiva & 1 & - & - & - & \multirow{12}{*}{$\begin{array}{l}\text { Não constam } \\
\text { empreendimen } \\
\text { tos certificados } \\
\text { no estado de } \\
\text { São Paulo }\end{array}$} & \multirow{12}{*}{$\begin{array}{l}\text { Não constam } \\
\text { empreendiment } \\
\text { os certificados } \\
\text { no estado de } \\
\text { São Paulo }\end{array}$} & \multirow{12}{*}{$\begin{array}{l}\text { Em } \\
\text { adequação } \\
\text { as normas } \\
\text { brasileiras }\end{array}$} \\
\hline Bairro & 1 & 6 & - & - & & & \\
\hline Banco & 7 & - & - & - & & & \\
\hline $\begin{array}{l}\text { Biblioteca/Centro } \\
\text { Cultural }\end{array}$ & 1 & - & - & - & & & \\
\hline Centro de Distribuição & 24 & - & - & - & & & \\
\hline Comercial & 65 & 6 & - & 14 & & & \\
\hline Data Center & 5 & - & - & - & & & \\
\hline Escola/Educação & 1 & 28 & - & 3 & & & \\
\hline Escritório & 23 & 17 & - & - & & & \\
\hline Hospedagem & 2 & 7 & - & 1 & & & \\
\hline Hospital & 5 & 1 & - & - & & & \\
\hline Industrial & 2 & 3 & - & - & & & \\
\hline
\end{tabular}




\section{TABELA 8: Quantidade de empreendimentos certificados no Estado de São Paulo e suas classes de uso.}

(CONTINUAÇÃO).

\begin{tabular}{|c|c|c|c|c|c|c|c|}
\hline \multirow{2}{*}{$\begin{array}{c}\text { Tipo de } \\
\text { empreendimento }\end{array}$} & \multicolumn{7}{|c|}{ Organismos Certificadores } \\
\hline & LEED & $\begin{array}{l}\text { AQUA- } \\
\text { HQE }\end{array}$ & $\begin{array}{c}\text { SELO CASA } \\
\text { AZUL }\end{array}$ & $\begin{array}{c}\text { Procel } \\
\text { Edificações }\end{array}$ & BREEAM & $\begin{array}{l}\text { QUALIVERDE - } \\
\text { PMRJ }\end{array}$ & DGNB \\
\hline Operação/Uso & - & 8 & - & - & \multirow{7}{*}{$\begin{array}{l}\text { Não constam } \\
\text { empreendimen } \\
\text { tos certificados } \\
\text { no estado de } \\
\text { São Paulo }\end{array}$} & \multirow{7}{*}{$\begin{array}{l}\text { Não constam } \\
\text { empreendiment } \\
\text { os certificados } \\
\text { no estado de } \\
\text { São Paulo }\end{array}$} & \multirow{7}{*}{$\begin{array}{l}\text { Em } \\
\text { adequação } \\
\text { as normas } \\
\text { brasileiras }\end{array}$} \\
\hline Outras & 3 & 2 & - & - & & & \\
\hline Pública & 1 & - & - & - & & & \\
\hline Reforma & - & 1 & - & - & & & \\
\hline Residencial & - & 69 & 3 & 20 & & & \\
\hline Restaurante & 8 & - & - & - & & & \\
\hline Supermercado & 3 & - & - & - & & & \\
\hline Total & 152 & 148 & 3 & 38 & 0 & 0 & 0 \\
\hline
\end{tabular}

TABELA 9: Porcentagem comparativa entre a quantidade de empreendimentos certificados e suas classes de uso.

Organismos Certificadores

Tipo de empreendimento

AQUA-HQE SELO CASA AZUL CAIXA Procel Edificações

\begin{tabular}{|c|c|c|c|c|c|c|c|c|}
\hline & Total & $\%$ & Total & $\%$ & Total & $\%$ & Total & $\%$ \\
\hline Arena Esportiva & 1 & 0,66 & - & - & - & - & - & - \\
\hline Bairro & 1 & 0,66 & 6 & 4,05 & - & - & - & - \\
\hline Banco & 7 & 4,61 & - & - & - & - & - & - \\
\hline Biblioteca/Centro Cultural & 1 & 0,66 & - & - & - & - & - & - \\
\hline Centro de Distribuição & 24 & 15,79 & - & - & - & - & - & - \\
\hline Comercial & 65 & 42,76 & 6 & 4,05 & - & - & 14 & 36,84 \\
\hline Data Center & 5 & 3,29 & - & - & - & - & - & - \\
\hline Escola/Educação & 1 & 0,66 & 28 & 18,92 & - & - & 3 & 7,89 \\
\hline Escritório & 23 & 15,13 & 17 & 11,49 & - & - & - & - \\
\hline Hospedagem & 2 & 1,32 & 7 & 4,73 & - & - & 1 & 2,63 \\
\hline Hospital & 5 & 3,29 & 1 & 0,68 & - & - & - & - \\
\hline Industrial & 2 & 1,32 & 3 & 2,03 & - & - & - & - \\
\hline Operação/Uso & - & - & 8 & 5,41 & - & - & - & - \\
\hline Outras & 3 & 1,97 & 2 & 1,35 & - & - & - & - \\
\hline Pública & 1 & 0,66 & - & - & - & - & - & - \\
\hline Reforma & - & - & 1 & 0,68 & - & - & - & - \\
\hline Residencial & - & - & 69 & 46,62 & 3 & 100 & 20 & 52,63 \\
\hline Restaurante & 8 & 5,26 & - & - & - & - & - & - \\
\hline Supermercado & 3 & 1,97 & - & - & - & - & - & - \\
\hline Total & 152 & 100 & 148 & 100 & 3 & 100 & 38 & 100 \\
\hline
\end{tabular}

O mercado da construção civil nacional é caracterizado pela grande quantidade de lançamentos de unidades habitacionais, casas e apartamento, com pequena contribuição dos demais tipos de empreendimentos. Entretanto, nos últimos anos o país passou por um grande crescimento econômico que incrementou os demais tipos de empreendimento.

Com isso o setor de serviços e industrial, Escritórios - 40 certificações, Comercial - 85,
Centro de Distribuição - 24 unidades, Bancos - 7 e Industrial com 5 certificações, apresentou números expressivos de certificação, pois esta passou a ser um diferencial do empreendimento, pois as ações de sustentabilidade diminuem as despesas com a manutenção da edificação como redução do consumo de água e eletricidade.

Por ser uma certificação que necessita de custos para sua realização nota-se que os empreendimentos públicos possuem uma pequena 
quantidade de certificações, como Arena esportiva, Biblioteca / Centro cultural. Apenas o setor educacional, com 32 certificações, se sobressaiu, fato explicado pelo aumento, principalmente, das vagas das universidades particulares em decorrência da política de financiamento estudantil. Escola, com apenas um certificado para cada empreendimento.

Por ser o organismo certificador que atua a mais tempo no país, a certificação LEED possui também a maior quantidade de empreendimentos certificados no estado de São Paulo, com 152 unidades, seguido pelo selo AQUA-HQE com 148. Como ponto negativo do mercado de certificações estão os organismos públicos nacionais com poucas unidades certificadas.

A consulta pela base de dados da certificação Procel Edificações, disponível no site <www.procelinfo.com.br>, indica uma grade quantidade de certificação por este selo, mas decorre que são considerados para fins de certificação unidades autônomas de um empreendimento, por exemplo, cada apartamento de uma torre comercial recebeu uma certificação.
Entretanto, para fins deste levantamento foi considerada a torre residencial como um empreendimento apenas. Com isso o Selo Procel Edificações possui um total de 38 empreendimentos certificados no Estado de São paulo.

A certificação emitida pela Caixa Econômica Federal, pelo denominado Selo Casa Azul Caixa, refere-se apenas aos empreendimentos objeto de financiamento por este banco, assim, todas as unidades certificadas no estado de São Paulo, apenas 3, são referente ao uso Residencial, habitações multifamiliares. Decorre que pela grande quantidade de obras financiadas por este banco, a quantidade de certificação poderia ser bem maior.

Em relação a classificação dos empreendimentos há ainda diferentes modalidades, esferas, de um mesmo selo certificador, permitindo assim classificar o empreendimento em diferentes níveis de "sustentabilidade", conforme a Tabela 10, que apresenta os dados do organismo certificador LEED.

TABELA 10: Classificação certificação LEED.

\begin{tabular}{|c|c|c|c|c|c|}
\hline \multirow{2}{*}{ Tipo de empreendimento } & \multicolumn{5}{|c|}{ LEED } \\
\hline & Platinum & Ouro & Prata & Certificado & Total \\
\hline Arena Esportiva & - & 1 & - & - & 1 \\
\hline Bairro & - & - & 1 & - & 1 \\
\hline Banco & - & 3 & 4 & - & 7 \\
\hline Biblioteca/Centro Cultural & - & 1 & - & - & 1 \\
\hline Centro de Distribuição & - & 5 & 10 & 9 & 24 \\
\hline Comercial & 4 & 34 & 20 & 7 & 65 \\
\hline Data Center & - & 5 & - & - & 5 \\
\hline Escola/Educação & - & 1 & - & - & 1 \\
\hline Escritório & 2 & 12 & 4 & 5 & 23 \\
\hline Hospedagem & - & - & 2 & - & 2 \\
\hline Hospital & - & 3 & 2 & - & 5 \\
\hline Industrial & - & - & 1 & 1 & 2 \\
\hline Operação/Uso & - & - & - & - & - \\
\hline Outras & 1 & 1 & - & 1 & 3 \\
\hline Pública & - & - & - & 1 & 1 \\
\hline Reforma & - & - & - & - & - \\
\hline Residencial & - & - & - & - & - \\
\hline Restaurante & - & - & 2 & 6 & 8 \\
\hline Supermercado & - & - & - & 3 & 3 \\
\hline Total & 7 & 66 & 46 & 33 & 152 \\
\hline Porcentagem & 4,61 & 43,42 & 30,26 & 21,71 & 100 \\
\hline
\end{tabular}


A certificação LEED é dividida em 4 níveis, conforme a pontuação obtida, máxima de 110 pontos, sendo assim classificada: Platinum: mais de 80 pontos; Ouro: de 60 a 79 pontos; Prata: de 50 a 59 pontos; Certificado: de 40 a 49 pontos.

Por ser o nível que exige maior pontuação e, portanto mais ações de sustentabilidade a classe Platinum da certificação LEED possui apenas 7 empreendimentos certificados. Entretanto, o nível Ouro - 66, Prata - 46, e Certificado - 33 certificações, fazem deste organismo o com maior quantidade de empreendimentos certificados no estado de São Paulo.

O destaque da certificação LEED fica com a grande quantidade de empreendimentos certificados destinados ao comércio com 65 unidades, Centro de distribuição com 24 e Escritórios com 23 certificações. Observa-se que o setor residencial que concentra a maior quantidade de empreendimentos no país não possui nenhuma certificação do selo LEED, necessitando de estudos junto ao organismo o motivo de não atender ao setor e também comparar as ações de sustentabilidade requeridas pelo organismo com a execução da obra de um empreendimento residencial.

Os empreendimentos certificados pelo Selo Casa Azul Caixa podem alcançar três classificações: Bronze, Prata e Ouro, sendo que a categoria Bronze se aplica somente a habitações de interesse social. Para a categoria Bronze, devem ser atendidos no mínimo 19 critérios obrigatórios. Para a categoria Prata, devem ser atendidos os 19 critérios obrigatórios e mais 6 critérios de livre escolha, e para a categoria Ouro, 19 critérios obrigatórios e 12 critérios de livre escolha. As escolhas dos critérios livres baseiam-se em 34 opções, além das 19 obrigatórias, havendo assim um total de 53 critérios.

Assim, os 3 empreendimentos certificados pelo Selo Casa Azul Caixa no estado de São Paulo são obras residenciais multifamiliares e de nível Ouro, isto é, estes se certificaram com os 19 critérios obrigatórios e no mínimo 12 outros critérios, Tabela 11 .

TABELA 11: Classificação certificação Selo Casa Azul Caixa.

\begin{tabular}{|c|c|c|c|}
\hline \multirow{2}{*}{ Tipo de empreendimento } & \multicolumn{3}{|c|}{ SELO CASA AZUL CAIXA } \\
\hline & Ouro & Prata & Bronze \\
\hline \multicolumn{4}{|l|}{ Arena Esportiva } \\
\hline \multicolumn{4}{|l|}{ Bairro } \\
\hline \multicolumn{4}{|l|}{ Banco } \\
\hline \multicolumn{4}{|l|}{ Biblioteca/Centro Cultural } \\
\hline \multicolumn{4}{|l|}{ Centro de Distribuição } \\
\hline \multicolumn{4}{|l|}{ Comercial } \\
\hline \multicolumn{4}{|l|}{ Data Center } \\
\hline \multicolumn{4}{|l|}{ Escola/Educação } \\
\hline \multicolumn{4}{|l|}{ Escritório } \\
\hline \multicolumn{4}{|l|}{ Hospedagem } \\
\hline \multicolumn{4}{|l|}{ Hospital } \\
\hline \multicolumn{4}{|l|}{ Industrial } \\
\hline \multicolumn{4}{|l|}{ Operação/Uso } \\
\hline \multicolumn{4}{|l|}{ Outras } \\
\hline \multicolumn{4}{|l|}{ Pública } \\
\hline \multicolumn{4}{|l|}{ Reforma } \\
\hline Residencial & 3 & & \\
\hline \multicolumn{4}{|l|}{ Restaurante } \\
\hline \multicolumn{4}{|l|}{ Supermercado } \\
\hline Total & 3 & 0 & 0 \\
\hline Porcentagem & 100 & & \\
\hline
\end{tabular}


A classificação da certificação Procel Edificações refere-se ao nível de eficiência energética de um edifício pode variar de $A$ (mais eficiente) a E (menos eficiente), conforme a pontuação obtida através pesos de uma equação que é variável para cada tipo de unidade e localização do empreendimento.

Esta equação leva em consideração vários fatores como: nível de eficiência da unidade habitacional autônoma; região geográfica na qual a edificação está localizada; equivalente numérico do desempenho térmico da envoltória da unidade habitacional autônoma quando ventilada naturalmente; equivalente numérico do sistema de aquecimento de água; pontuação atribuída a iniciativas que aumentem a eficiência da edificação, entre muitos outros fatores. A escala de pontuação é apresentação na Tabela 12. A Tabela 13 apresenta os empreendimentos certificados pelo selo Procel Edificações, ilustrando os tipos de empreendimentos e o nível de certificação.

TABELA 12: Classificação do nível de eficiência de acordo com a pontuação obtida - Procel Edificações.

\begin{tabular}{ll} 
Pontuação (PT) & Nível de Eficiência \\
\hline $\mathrm{PT} \geq 4,5$ & $\mathrm{~A}$ \\
\hline $3,5 \leq \mathrm{PT} \geq 4,5$ & $\mathrm{~B}$ \\
\hline $2,5 \leq \mathrm{PT} \geq 3,5$ & $\mathrm{C}$ \\
\hline $1,5 \leq \mathrm{PT} \geq 2,5$ & $\mathrm{D}$ \\
\hline $\mathrm{PT}<1,5$ & $\mathrm{E}$ \\
\hline
\end{tabular}

FONTE: Autoria própria.

TABELA 13: Classificação certificação Procel Edificações.

\begin{tabular}{|c|c|c|c|c|}
\hline \multirow{2}{*}{ Tipo de empreendimento } & \multicolumn{4}{|c|}{ PROCEL EDIFICAÇÕES } \\
\hline & A & B & C & TOTAL \\
\hline \multicolumn{5}{|l|}{ Arena Esportiva } \\
\hline \multicolumn{5}{|l|}{ Bairro } \\
\hline \multicolumn{5}{|l|}{ Banco } \\
\hline \multicolumn{5}{|l|}{ Biblioteca/Centro Cultural } \\
\hline \multicolumn{5}{|l|}{ Centro de Distribuição } \\
\hline Comercial & 13 & & 1 & 14 \\
\hline \multicolumn{5}{|l|}{ Data Center } \\
\hline Escola/Educação & 3 & & & 3 \\
\hline \multicolumn{5}{|l|}{ Escritório } \\
\hline Hospedagem & 1 & & & 1 \\
\hline \multicolumn{5}{|l|}{ Hospital } \\
\hline \multicolumn{5}{|l|}{ Industrial } \\
\hline \multicolumn{5}{|l|}{ Operação/Uso } \\
\hline \multicolumn{5}{|l|}{ Outras } \\
\hline \multicolumn{5}{|l|}{ Pública } \\
\hline \multicolumn{5}{|l|}{ Reforma } \\
\hline Residencial & 14 & 5 & 1 & 20 \\
\hline \multicolumn{5}{|l|}{ Restaurante } \\
\hline \multicolumn{5}{|l|}{ Supermercado } \\
\hline Total & 31 & 5 & 2 & 38 \\
\hline Porcentagem & 81,58 & 13,16 & 5,26 & 100 \\
\hline
\end{tabular}


A grande maioria das edificações certificadas pelo selo Procel Edificações obtiveram o nível A, 31 unidades representando $81,58 \%$ do total. Com a maior quantidade de empreendimentos residenciais com 14 unidades e comerciais com 13 certificações.

De nível $\mathrm{B}$ há 5 unidades, 13,16\%, todas elas empreendimentos de uso Residencial. Com apenas 2 empreendimentos no nível C, 5,26\%, sendo 1 de uso Comercial e 1 de uso Residencial, observa-se que nas certificações do Selo Procel Edificações há maior preocupação em atingir os maiores índices, pois isso trará economia no consumo de energia elétrica.

\section{CONCLUSÕES}

A realidade brasileira decorrente da certificação dos empreendimentos da construção civil sustentáveis ainda é pequena quando comparada a outros países, que possuem populações inferiores e inclusive quando comparada ao número de lançamentos de empreendimentos nos últimos anos. Mas o mercado é promissor, pois se multiplicam no país profissionais credenciados pelos organismos certificadores para desenvolver e implantar as metodologias de cada certificação.

Entretanto, dos sete selos atuantes no país, quatro deles são adaptações de certificação ao mercado nacional, AQUA-HQE, BREEAM, DGNB e LEED, o que pode contribuir para a baixa adesão dos novos empreendimentos, pois podem conter critérios de avaliação difíceis de serem aplicados ou em desacordo com os "padrões" de execução de obras amplamente difundidos no Brasil.

Já os certificadores nacionais, Procel Edificações, Selo Casa Azul da Caixa e Qualiverde são pouco escolhidos pelos empreendedores, devido principalmente a baixa divulgação de sua existência, mas que por serem realizações nacionais, estão mais adaptados a realidade brasileira.

Devido a grande expansão de obras financiadas pela Caixa Econômica Federal através do programa federal Minha Casa, Minha Vida, este número de empreendimentos certificados pelo Selo Casa Azul da Caixa, apenas 3 no estado de São Paulo, poderia ser bem maior, visto as melhorias que confeririam às edificações. Assim o setor da construção civil brasileira perdeu um grande fato para aumentar a quantidade de obras certificadas em relação às ações de sustentabilidade.

Ações essas que aliadas ao financiamento público e a grande quantidade de empreendimentos realizados poderia contribuir em metas e ações mais acessíveis aos grandes empreendedores e também poderiam estar alinhadas as obras de pequeno porte, realizadas diretamente por seus proprietários.

A certificação Procel Edificações, deveria aproveitar a ótima reputação que o selo Procel tem para os equipamentos elétricos, e estender para o setor da construção civil esta expertise, fazendo com que este selo fosse um diferencial para a aquisição de um empreendimento, assim como é nos aparelhos eletrônicos.

A ação da Secretaria de Urbanismo da Prefeitura Municipal do Rio de Janeiro com a elaboração da certificação Qualiverde é digna de reconhecimento, ainda mais com sua aplicação as obras das Olimpíadas do Rio em 2016, é aguardar para ver as certificações concretizadas e seus benefícios a sociedade, e que metodologia seja difundida e aproveitada por outras cidades brasileiras.

\section{REFERÊNCIAS BIBLIOGRÁFICAS}

AQUA. Informações referente a certificação Aqua. 2016. Disponível em: <http://vanzolini.org.br/hotsiteaqua.asp?cod_site=104>. Acesso em: 30/12/2016.

BREEAM. Informações referente a certificação BREEAM. 2016.2 Disponível em: <http://www.breeam.org>. Acesso em: 30/12/2016.

CAIXA ECONÔMICA FEDERAL - CAIXA. Boas práticas para habitação mais sustentável. Coordenadores Vanderley Moacyr John, Racine Tadeu Araújo Prado. São Paulo: Páginas \& Letras - Editora e Gráfica, 2010. 202p.

CAIXA ECONÔMICA FEDERAL - CAIXA. Informações referente a certificação Selo Casa Azul Caixa. 2016. Disponível em: <http://www.caixa.gov.br/sustentabilidade/produtos- 
servicos/selo-casa-azul/Paginas/default.aspx>. Acesso em: 30/12/2016.

CAMPOS, M. A. ; ARGOLLO FERRÃO, A. M. Engenharia de Empreendimentos Sustentáveis no Brasil: identificação dos selos certificadores nacionais. In: Congresso Técnico Científico da Engenharia e da Agronomia, 2 [CONTECC'2015], 2015, Fortaleza [CE]. Anais.... Brasília [DF]: CONFEA, 2015. v. 1. p. 1-4.

DGNB. Informações referente a certificação DGNB. 2016. Disponível em: <http://www.dgnb.de/en>. Acesso em: $30 / 12 / 2016$.

LEED. Informações referente a certificação LEED. 2016. Disponível em: <http://www.gbcbrasil.org.br>. Acesso em: $30 / 12 / 2016$.
MINISTÉRIO DO MEIO AMBIENTE - MMA. Cidades Sustentáveis. $\quad \mathrm{s} . / \mathrm{d}$. Disponível em: <http://www.mma.gov.br/cidadessustentaveis/urbanismosustentavel/constru\%C3\%A7\%C3\%A3osustent\%C3\%A1vel>. Acesso em: 30/12/2016.

PREFEITURA MUNICIPAL DO RIO DE JANEIRO - PMRJ. Informações referente a certificação Qualiverde. 2013. Disponível em: <http://www.rio.rj.gov.br/web/smu/exibeconteudo?id= 4368435>. Acesso em: 30/12/2016.

PROCEL. Informações referente a certificação PROCEL EDIFICAÇÕES. 2016.2 Disponível em: <http://www.procelinfo.com.br/main.asp?View=\{8E03D CDE-FAE6-470C-90CB-922E4DD0542C\}>. Acesso: $30 / 12 / 2016$. 